\title{
Rare combined variations of the coeliac trunk, accessory hepatic and gastric arteries with co-occurrence of double cystic arteries
}

\author{
A. Mazurek, A. Juszczak@i), J.A. Walocha®D, A. Pasternak® \\ Department of Anatomy, Jagiellonian University Medical College, Krakow, Poland \\ [Received: 22 March 2020; Accepted: 29 April 2020]
}

\begin{abstract}
Many variations of the coeliac trunk and hepatic or gallbladder arterial supply have been reported before in many cadaveric and radiologic studies. In this case we present combined anomalies observed in dissected cadaver of a 73-year-old female. The left gastric artery arises directly from the abdominal aorta and gives two branches: the right inferior phrenic artery in the proximal part and the accessory left hepatic artery in the distal part. The coeliac trunk is bifurcated into the common hepatic artery and the splenic artery. The right gastric artery emerges from the left hepatic artery. The right hepatic artery gives two cystic arteries and the accessory right hepatic artery is noticed arising from the posterior superior pancreaticoduodenal artery. The deep cystic artery and the right inferior phrenic artery give hepatic branches. Also, we noticed small accessory biliary duct going to the cystic duct. This complexity of the arterial supply with anomaly of the biliary ducts has many surgical implications which will be herein discussed. (Folia Morphol 2021; 80, 2: 460-466)
\end{abstract}

Key words: anatomical variations, accessory hepatic artery, gastric artery, double cystic arteries, right inferior phrenic artery

\section{INTRODUCTION}

The importance of the arterial supply of the liver, gallbladder and upper gastrointestinal tract has been noticed in plenty of surgical procedures. Calot (1891) [7] was the first, who emphasized the position of the cystic artery during cholecystectomy. Adachi (1928) [1] elaborated the classification of variations of the coeliac trunk, which is also used currently, and Michels [23] was one of the first researches who described and classified the variability of the hepatic arterial supply. According to recent reviews, the most common variation in types of the incomplete coeliac trunk was the hepatosplenic trunk present in $3.88 \%$ of cases with the left gastric artery (LGA) originating from the ab- dominal aorta in $99.87 \%$ [35]. The right gastric artery (RGA) most frequently goes from the proper hepatic artery - in 53\% of cases [11]. Accessory or replaced hepatic arteries are observed in $30.8 \%$. The accessory left hepatic artery (LHA), which occurs in $8.2 \%$, mostly arises from the LGA (7.9\%) and the accessory right hepatic artery (RHA) described in $5.6 \%$ of cases with the most often origin from the superior mesenteric artery (SMA) in 5.4\% [17]. Double cystic arteries (or multiple cystic arteries) are observed in $8.9 \%$ [3]. The right inferior phrenic artery most frequently originates from the abdominal aorta [32]. Our case comprises more or less frequent variations of all mentioned arteries with accessory branches to liver, which makes 


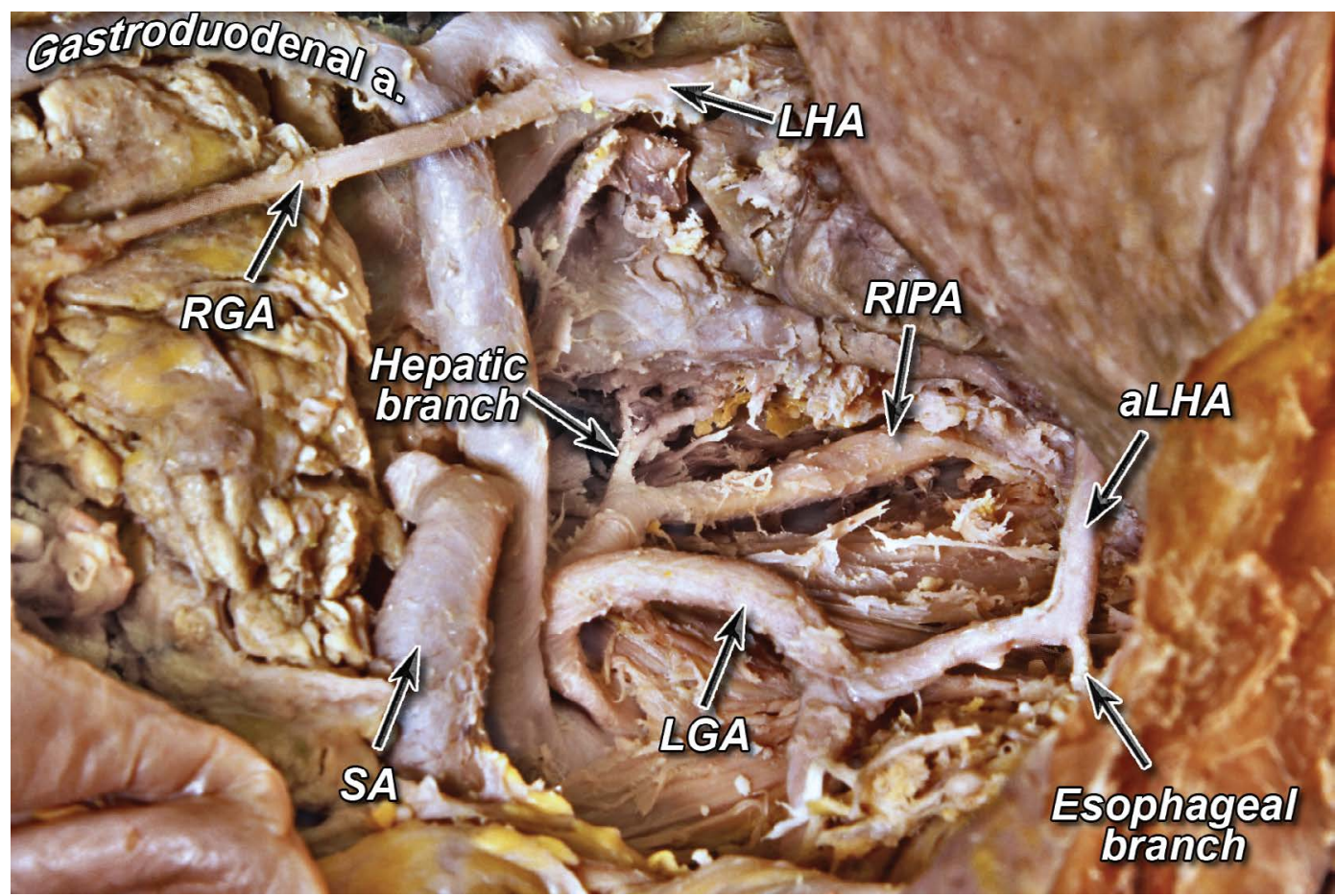

Figure 1. Emphasized small branches to the oesophagus and the liver; LHA — left hepatic artery; aLHA — accessory left hepatic artery; LGA — left gastric artery; RGA — right gastric artery; RIPA — right inferior phrenic artery; SA — splenic artery.

it unique and allows us to show the significance of them in clinical practice for example in transplantology, cholecystectomy or surgical oncology.

\section{CASE REPORT}

During a routine dissection for teaching purpose of the 73 -year-old female $10 \%$ formalin-fixed cadaver many multiple anomalies were observed. In the abdominal cavity any previous surgical interventions were not noted. At the level of Th12-L1 the LGA (4.74 $\mathrm{mm}$ in diameter) arose separately from the abdominal aorta (18.15 $\mathrm{mm}$ in diameter) curving a geniculate flexure and branched off the right inferior phrenic artery (RIPA; $2.75 \mathrm{~mm}$ in width) at $8.51 \mathrm{~mm}$ from the origin and heading up gave the second branch, i.e. the accessory left hepatic artery (aLHA; $2.89 \mathrm{~mm}$ in diameter) after $25.15 \mathrm{~mm}$ in length course from the proximal branching. The small hepatic branch $(1.17 \mathrm{~mm}$ in diameter) arose from the RIPA at $18.18 \mathrm{~mm}$ distal from the beginning. The aLHA gave small oesophageal branch only $1.30 \mathrm{~mm}$ in diameter (Fig. 1). The hepatosplenic trunk (5.33 $\mathrm{mm}$ in width) originated from the abdominal aorta $4.39 \mathrm{~mm}$ below the LGA and divided into the common hepatic artery (CHA) and the splenic artery (SA). The CHA (4.67 mm in width) coursed along the upper margin of the pancreas and branched into the proper hepatic artery (PHA) and the gastroduodenal artery (GDA) at $27.41 \mathrm{~mm}$ from the beginning. The PHA (3.68 $\mathrm{mm}$ in diameter and $9.07 \mathrm{~mm}$ in length) ended up with bifurcating into the RHA and the LHA. The LHA (2.87 in width) branched to the RGA ( $1.79 \mathrm{~mm}$ diameter) at the $2.40 \mathrm{~mm}$ from the origin and the RGA run down $25.94 \mathrm{~mm}$ to the lesser curvature crossing the CHA above (Fig. 2). The RHA (3.34 mm in diameter) passed behind the common hepatic duct (CHD) at the $15.46 \mathrm{~mm}$ from the beginning of its course and gave rise to the superficial cystic artery (1.63 $\mathrm{mm}$ in width) $3.20 \mathrm{~mm}$ after crossing the CHD (diameter $7.07 \mathrm{~mm}$ ), gave small branch to the liver and at the $5.24 \mathrm{~mm}$ from the first branching and gave the deep cystic artery (dCA; $1.48 \mathrm{~mm}$ in diameter) from which also arose a small hepatic branch (1.05 mm in width) (Fig. 3). The GDA at the $16.14 \mathrm{~mm}$ from the origin feeding branches to the right gastroepiploic artery $(2.62 \mathrm{~mm})$ and the anterior superior pancreaticoduodenal artery (1.95 $\mathrm{mm}$ diameter) and then the GDA run down as the posterior superior pancreaticoduodenal artery (PSPD) along the head of pancreas giving the proximal branch (at the $16.37 \mathrm{~mm}$ from the previous branching), travelled $9.89 \mathrm{~mm}$ and divided into the accessory right hepatic artery (aRHA) and the distal branch $(1.93 \mathrm{~mm})$. The aRHA $(2.10 \mathrm{~mm}$ in diameter and $40.32 \mathrm{~mm}$ in length) run parallel to 


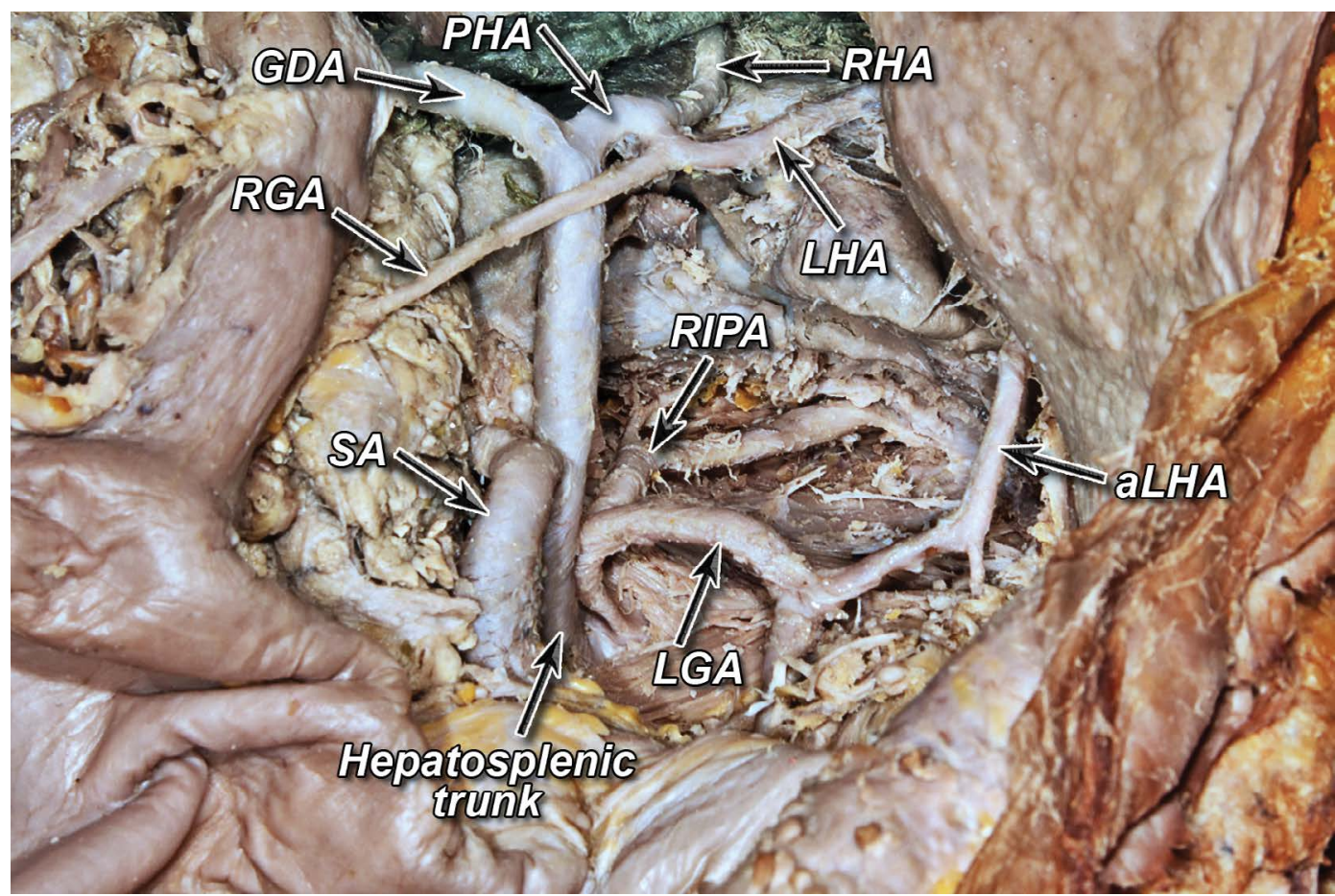

Figure 2. Complex variations of the coeliac trunk. Left gastric artery (LGA) arises independently from the abdominal aorta and branches to the right inferior phrenic artery (RIPA) which gives off small hepatic branch and in the distal course from the LGA arises the accessory left hepatic artery. Right gastric artery (RGA) originates from the left hepatic artery (LHA); aLHA — accessory left hepatic artery; GDA — gastroduodenal artery; PHA — proper hepatic artery; RHA — right hepatic artery; SA — splenic artery.
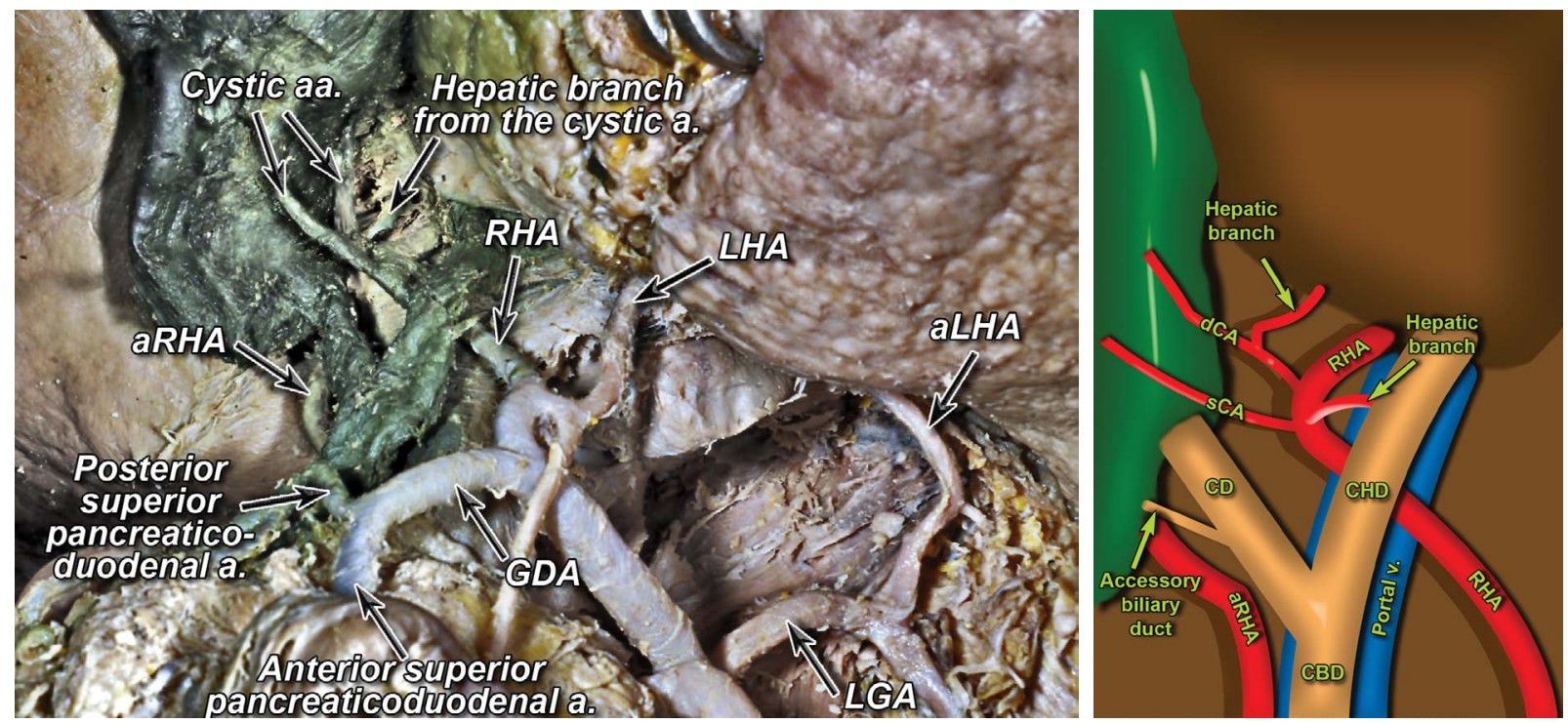

Figure 3. Cystic arteries with branches to the liver arising from the deep cystic artery (dCA) and right hepatic artery (RHA); sCA - superficial cystic artery; LHA — left hepatic artery; aLHA — accessory left hepatic artery; aRHA — accessory right hepatic artery; GDA — gastroduodenal artery; $\mathrm{CBD}$ — common biliary duct; $\mathrm{CD}$ — cystic duct; CHD — common hepatic duct.

the common bile duct and travelled to the biliary fossa dividing into two branches before entering the liver. In the vicinity of this area the small accessory biliary duct $(0.52 \mathrm{~mm}$ in width) going directly from $V$ segment of the liver and at $14.58 \mathrm{~mm}$ from the origin merged to the cystic duct in the midway of its course (Fig. 4). Diameters of observed abnormal arteries are summarised in Table 1.

In this case, the arterial blood supply for the liver was supported by five arteries: RHA, LHA, aRHA gave 


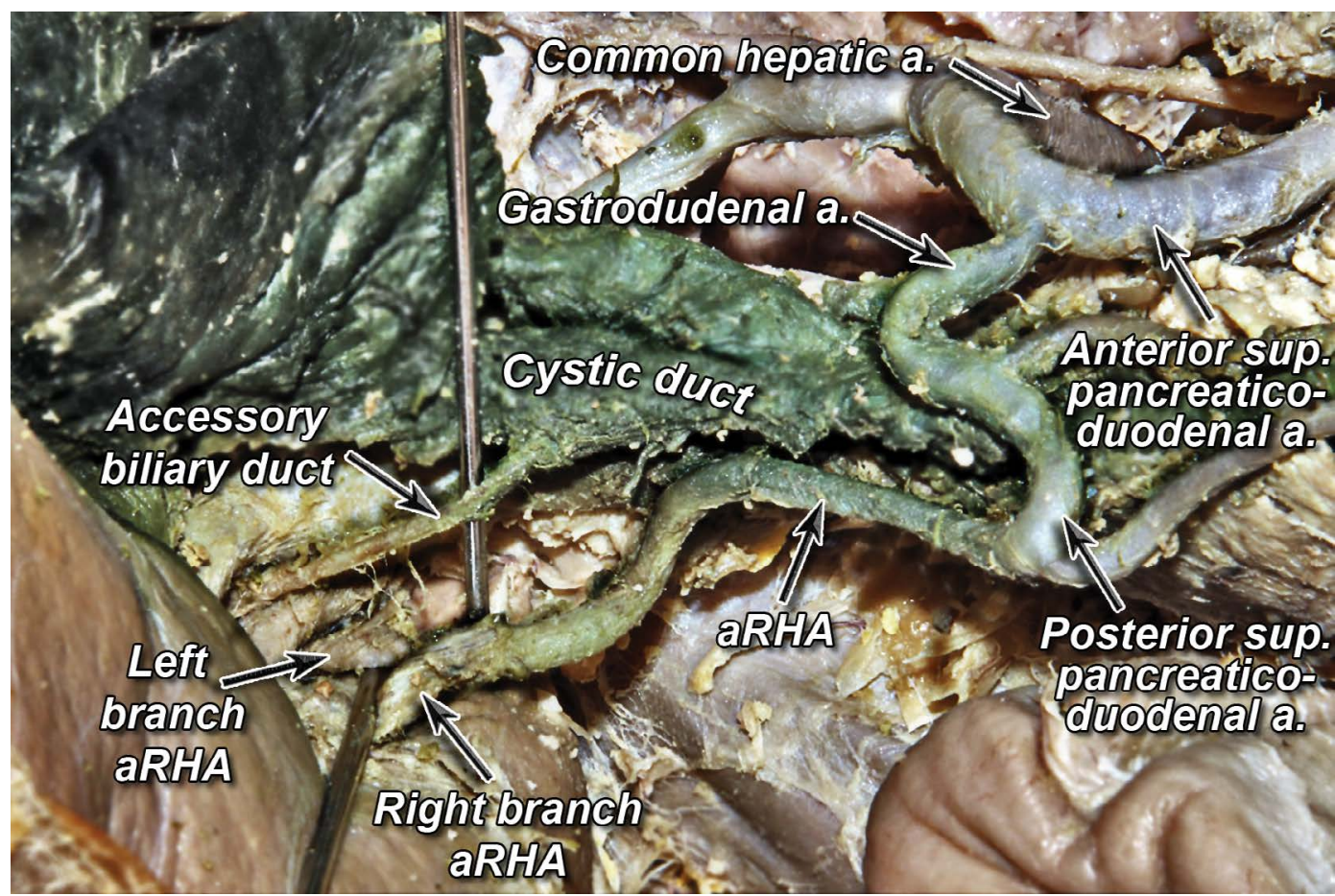

Figure 4. Accessory right hepatic artery (aRHA) emerges from the posterior superior pancreaticoduodenal artery and travels parallel to the common bile duct to the gallbladder fossa, dividing into right and left branch. Small accessory biliary duct (also known as cystohepatic duct) goes directly from the liver (V segment) and reaches the cystic duct at its halfway.

Table 1. Summarised measurements of abnormal arteries in our case

\begin{tabular}{lc}
\hline Artery & Diameter [mm] \\
\hline Left gastric artery & 4.74 \\
Right gastric artery & 1.79 \\
Right inferior phrenic artery & 2.75 \\
Accessory left hepatic artery & 2.89 \\
Accessory right hepatic artery & 2.10 \\
Deep cystic artery & 1.48 \\
Superficial cystic artery & 1.63 \\
\hline
\end{tabular}

off the PSPD, aLHA from the LGA, RIPA and the small branch arising from the dCA.

\section{DISCUSSION}

The variations of the incomplete coeliac trunk were repeatedly described by researches. As we mentioned, the hepatosplenic trunk was observed in $3.88 \%$ of cases with the abdominal aorta as the origin feeding of the LGA in $99.87 \%$. More rarely the LGA arises from the SMA $(0.76 \%)$ or it is absent $(0.38 \%)$ [35]. The prevalence of the cases where the LGA gave off the RIPA is estimated at $2 \%$ to $4.1 \%$ [25]. Some of the researches distinguished the gastrophrenic trunk [16,
$22,26,28,32,37$ ] as the common origin of the inferior phrenic artery and the LGA. The majority of the used classifications do not perceive it as a trunk and in most cases it is recognised in association with presence of the hepatosplenomesenteric trunk [16, 22, 26, 28] but the co-occurrence with the hepatosplenic trunk also was described $[32,37]$. According to the classification proposed by Whitley et al. [35], this type of trunk is not included but we came to the conclusion that it is important to mention this fact. Inferior phrenic arteries more frequently originate asymmetrically [5]. Right inferior phrenic arteries commonly arise from the abdominal aorta (49\%) or the coeliac trunk (41\%), less frequently from the LGA or renal arteries (5.5\%) $[4,5,19]$. Aslaner et al. [4] noted higher frequency of the RIPA arising from the renal artery with co-occurrence of the incomplete coeliac trunk.

The anomaly of the RGA arising from the LHA was observed by Yamagami et al. [36] in 25.3\% of cases and the Eckmann and Krahn [11] estimated the frequency to be $15 \%$.

Variations of the hepatic arteries were commonly described by many authors [9, 15, 17, 23]. In the review presented by the Cirrochi et al. [9], the aLHA originating from the LGA was noticed in $3.60 \%$ (694/19284) of cases (including Michels' and Hiatt's 
Table 2. Prevalence of variations observed in our case

\begin{tabular}{lc}
\hline Variation & Frequency (\%) \\
\hline RIPA from LGA & $2-4.1$ \\
Hepatosplenic trunk (LGA from abdominal aorta) & 3.87 \\
RGA from hepatic artery & $15-25.3$ \\
aLHA from LGA & $3.6-8.2$ \\
aRHA from GDA & 0.04 \\
Multiple CAs & 8.9 \\
Cystohepatic duct (including cholecystohepatic duct) & $0.2-2.3$
\end{tabular}

aLHA — accessory left hepatic artery; aRHA — accessory right hepatic artery; CA cystic artery; GDA - gastroduodenal artery; LGA — left gastric artery; RGA — right gastric artery; RIPA — right inferior phrenic artery

findings). Jin et al. [17] estimated the prevalence of the aLHA originating from the LGA to be $8.2 \%$ (total cases 10,211 ). The aRHA was observed in $5.6 \%$ of cases. Although the cases of aRHA arising from the GDA were revealed in approximately $0.04 \%$ (4 of 10,211 cases which also included branches of the GDA) [17], the pancreaticoduodenal artery branched the aRHA in some of them [2]. Juszczak et al. [18] presented similar interesting case wherein also both accessory hepatic arteries were observed, aLHA arising from the LGA which arose independently from the abdominal aorta and aRHA from SMA as the feeding origin but contrary to our case the PHA did not divide into two hepatic arteries. Also, they observed both inferior phrenic arteries originating from the hepatosplenic trunk (positioned opposite to the vertebral L1 level) and both branched off superior adrenal arteries [18].

Andall et al. [3] revealed the weighted percentage of the multiple cystic arteries was circa $8.9 \%$, with the highest noted number of arteries being four, but some researchers found this variation in $30.2 \%$ [24] and $28.3 \%$ [6] of cases. Small accessory biliary duct emerging from the liver parenchyma found in our case is classified as cystohepatic duct and the incidence of its variation (also including the cholecystohepatic duct which directly drains to the gallbladder) ranges between $0.2 \%$ and $2.3 \%$. This variation might occur with normal CHD and common biliary duct anatomy likewise in our case [30, 31]. Frequencies of observed variations were presented in Table 2.

Variations observed in our case reflect processes during foetal development. The most common variation is trifurcation of the coeliac trunk (LGA, CHA and SA) separately to the SMA which is generated by interruption of anastomosis between third and fourth ventral mesenteric root [33]. The interruption between 1 and 2 mesenteric roots with termination of anastomosis between 3 and 4 roots cause occurrence of LGA independently originating from abdominal aorta with hepatosplenic trunk. Higher prevalence of some variations of hepatic arteries also could be explained by analysing the embryological development. Primarily the LHA arises from the LGA and the RHA from SMA and there is an absence of the PHA which originates from the $\mathrm{CHA}$ after its bifurcation. If hepatic branches of the LGA or SMA with division PHA into RHA and LHA are preserved, these branches are named as accessory left hepatic artery and accessory right hepatic artery respectively. This fact clarifies high frequency of aLHA originating from the LGA and aRHA from the SMA. Grugacz et al. reported case wherein all foetal origins of hepatic arteries were preserved with presence of the middle hepatic artery feeding IV segment of the liver [14]. In our findings we observed abnormal primary right hepatic artery arising from branch of the GDA transitioned during development to the aRHA. Mahajan et al. presented similar case of preserved foetal pattern of liver's blood supply, also they reported occurrence of oesophageal branch arising from replaced LHA which emerged from LGA [21].

Doubled cystic arteries with co-occurrence of accessory hepatic arteries were reported by some authors. Loukas et al. [20] described case wherein a small accessory cystic artery (CA) arose from PSPD with aLHA originating from LGA which emerged independently from abdominal aorta and the hepatosplenic trunk also was observed. Polguj et al. [27] revealed variant of GDA which gave off both accessory CA and aRHA which also gave off CA. No other anomalies of coeliac trunk and hepatobiliary vasculature were observed in this case. Dolenšek [10] described occurrence of doubled CAs (larger sCA and small dCA) both of which arose from aRHA. Similarly to our case both accessory hepatic arteries were present but the aRHA emerged from the SMA and the PHA was trifurcated into left, middle and right hepatic arteries with coexistence of classical trifurcation of the coeliac trunk. According to Andall et al. [3], the prevalence of CA arising from abnormal RHA (replaced or accessory) is estimated at $5.58 \%$. In this research the frequency of GDA and PSPD as origin feeding of CA was $1.94 \%$ and $0.07 \%$ respectively.

Vascular abnormalities described in this case are significant in surgical practice. Using the critical view of safety method during laparoscopic cholecystec- 
tomy the surgeon has to precisely identify vascular structures in the hepatobiliary triangle. In cases, wherein the origin feeding of the cystic artery is different than the RHA (LHA or GDA) or course of the cystic artery is anteriorly to the common hepatic duct, there is a high risk of ligation. Also, in variant of multiple cystic arteries one of the CAs could be overlooked leading to uncontrolled bleeding [3]. Although the postcholecystectomy bile leaks occur in $0.2-2 \%$ of cases, the surgeon should be careful with presence of the subvesical ducts during the procedure, especially if this duct drains to the cystic duct $[29,31]$.

Knowledge about variations of accessory or replaced hepatic arteries is crucial in planning intra-arterial chemotherapy in treatment of cancers or metastases (mainly metastases of the colorectal cancer) in liver because it is essential to find appropriate artery feeding occupied lobe by neoplasm to accurately arrange hepatic arterial infusion pump placement and avoid infusion to arteries supplying the other organs. This procedure also include the embolisation of the extra-hepatic arteries, such as RGA, pyloric artery and GDA $[8,13]$ and if accessory or replaced hepatic arteries arising from the embolised artery was not recognised it could cause hepatic ischaemia. In procedures of chemo-embolisation and radio-embolisation it is significant to consider blood circulation in interested segment provided by the extra-hepatic arteries including inferior phrenic arteries which usually supply segments I, II and VII. LGA and CA are also hepatic feeders, II, III segments and peri-vesicular region, respectively [13]. The RIPA is mentioned as one of the main extrahepatic collateral arteries which are supplying the hepatocellular carcinoma and usually in this case the diameter of the RIPA is larger than the diameter of the LIPA. The width of the RIPA feeding neoplasm in the liver ranged from 2 to $3.2 \mathrm{~mm}$ [5] and in another research the diameter greater than $2.5 \mathrm{~mm}$ was considered as indication of present collateral circulation [4].

Vascular anatomy of liver is also significant in transplantology, especially in living-donor liver transplantation, wherein right (adult recipient) or left lobe (paediatric recipient) is harvested because thorough analysis of liver vessels enables to preserve proper blood circulation in retained donor's lobe and guarantees appropriate liver regeneration. In surgical practice preservation of all found anomalies of hepatic arteries is preferred $[8,34]$ but some of them could be difficult to find during the procedure, for example the accessory LHA arising from the LGA [34]. Also, anomalies of the hepatic biliary vascularisation should be verified (especially in harvesting the right lobe) to avoid bile leakage in recipients, which leads to graft rejection $[8,12]$.

\section{CONCLUSIONS}

Anatomical variations of the arterial blood supply of upper part of the abdomen have great importance in many surgical procedures and they are strongly associated with embryological development. Acquaintance about branching patterns of cystic arteries and hepatic arteries is significant in planning cholecystectomy or liver transplantation and in these procedures existence of accessory biliary duct should be concerned to avoid postsurgical complications. Abnormal branches to liver or gallbladder arising from gastroduodenal artery or posterior superior pancreaticoduodenal artery are rarely observed and knowledge about them facilitates better understanding about vascularisation of these organs.

\section{REFERENCES}

1. Adachi B. Das Arteriensystem der Japaner, vol II. Maruzen, Kyoto 1928: 16-64.

2. Ahn CS, Lee SG, Hwang S, et al. Anatomic variation of the right hepatic artery and its reconstruction for living donor liver transplantation using right lobe graft. Transplant Proc. 2005; 37(2): 1067-1069, doi: 10.1016/j.transproceed.2005.01.068, indexed in Pubmed: 15848624.

3. Andall RG, Matusz P, du Plessis M, et al. The clinical anatomy of cystic artery variations: a review of over 9800 cases. Surg Radiol Anat. 2016; 38(5): 529-539, doi: 10.1007/ s00276-015-1600-y, indexed in Pubmed: 26698600.

4. Aslaner R, Pekcevik $Y$, Sahin $H$, et al. Variations in the origin of inferior phrenic arteries and their relationship to celiac axis variations on CT angiography. Korean J Radiol. 2017; 18(2): 336-344, doi: 10.3348/kjr.2017.18.2.336, indexed in Pubmed: 28246513.

5. Basile A, Tsetis D, Montineri A, et al. MDCT anatomic assessment of right inferior phrenic artery origin related to potential supply to hepatocellular carcinoma and its embolization. Cardiovasc Intervent Radiol. 2008; 31(2): 349-358, doi: 10.1007/s00270-007-9236-x, indexed in Pubmed: 18071790.

6. Browne EZ. Variations in origin and course of the hepatic artery and its branches. Surgery. 1940; 8: 424-445.

7. Calot JF. De la cholecystecomie. Dissertation, Med Frc de Paris 1891.

8. Catalano $\mathrm{OA}$, Singh $\mathrm{AH}$, Uppot RN, et al. Vascular and biliary variants in the liver: implications for liver surgery. Radiographics. 2008; 28(2): 359-378, doi: 10.1148/ rg.282075099, indexed in Pubmed: 18349445 .

9. Cirocchi R, D'Andrea V, Amato B, et al. Aberrant left hepatic arteries arising from left gastric arteries and their clinical importance. Surgeon. 2020; 18(2): 100-112, doi: 10.1016/j. surge.2019.06.002, indexed in Pubmed: 31337536.

10. Dolenšek J. Triple arterial blood supply to the liver and double cystic arteries. Folia Morphol. 2017; 76(3): 523- 
-526, doi: 10.5603/FM.a2017.0008, indexed in Pubmed: 28150275.

11. Eckmann I, Krahn V. [Frequency of different sites of origin of the right gastric artery]. Anat Anz. 1984; 155(1-5): 65-70, indexed in Pubmed: 6721206.

12. Fang $C$, Yan S, Zheng S. Bile Leakage after Liver Transplantation. Open Med (Wars). 2017; 12: 424-429, doi: 10.1515/med-2017-0062, indexed in Pubmed: 29318188.

13. Favelier S, Germain T, Genson PY, et al. Anatomy of liver arteries for interventional radiology. Diagn Interv Imaging. 2015; 96(6): 537-546, doi: 10.1016/j.diii.2013.12.001, indexed in Pubmed: 24534562.

14. Gurgacz AM, Horbaczewska A, Klimek-Piotrowska W, et al. Variations in hepatic vascularisation: lack of a proper hepatic artery. Two case reports. Folia Morphol. 2011; 70(2): 130-134, indexed in Pubmed: 21630235.

15. Hiatt JR, Gabbay J, Busuttil RW. Surgical anatomy of the hepatic arteries in 1000 cases. Ann Surg. 1994; 220(1): 50-52, doi: 10.1097/00000658-199407000-00008, indexed in Pubmed: 8024358.

16. Hirai $Y$, Yamaki $K$, Saga T, et al. An anomalous case of the hepato-spleno-mesenteric and the gastro-phrenic trunks independently arising from the abdominal aorta. Kurume Med J. 2000; 47(2): 189-192, doi: 10.2739/kurumemedj.47.189, indexed in Pubmed: 10948660.

17. Jin W, Dong M, Pan J, et al. Rare combined variations of accessory left hepatic artery and accessory right hepatic artery: a case report and literature review. Surg Radiol Anat. 2020; 42(4): 443-447, doi: 10.1007/s00276-01902396-4, indexed in Pubmed: 31811353.

18. Juszczak A, Solewski B, Loukas M, et al. Unusual branching pattern of celiac trunk associated with supernumerary hepatic arteries and abnormal adrenal venous drainage: case study and review of the literature. Folia Med Cracov. 2017; 57(3): 29-36, indexed in Pubmed: 29263452.

19. Kim HC, Chung JW, Lee W, et al. Recognizing extrahepatic collateral vessels that supply hepatocellular carcinoma to avoid complications of transcatheter arterial chemoembolization. Radiographics. 2005; 25 Suppl 1: S25-S39, doi: 10.1148/rg.25si055508, indexed in Pubmed: 16227494.

20. Loukas M, Fergurson A, Louis RG, et al. Multiple variations of the hepatobiliary vasculature including double cystic arteries, accessory left hepatic artery and hepatosplenic trunk: a case report. Surg Radiol Anat. 2006; 28(5): 525-528, doi: 10.1007/ s00276-006-0138-4, indexed in Pubmed: 17006621.

21. Mahajan A, Tiwari S, Mishra S. A Unique Conglomeration of Variations in the Celiac, Hepatic, and Superior Mesenteric Artery: A Clinico-Embryological Perspective. Int J Appl Basic Med Res. 2018; 8(4): 256-258, doi: 10.4103/ ijabmr.IJABMR_395_17, indexed in Pubmed: 30598915.

22. Matusz $P$, Loukas $M$, lacob $N$, et al. Common stem origin of left gastric, right and left inferior phrenic arteries, in association with a hepatosplenomesenteric trunk, independently arising from the abdominal aorta: case report using MDCT angiography. Clin Anat. 2013; 26(8): 980-983, doi: 10.1002/ca.22204, indexed in Pubmed: 23255305.

23. Michels NA. Newer anatomy of the liver and its variant blood supply and collateral circulation. Am J Surg. 1966; 112(3): 337-347, doi: 10.1016/0002-9610(66)90201-7, indexed in Pubmed: 5917302.

24. Mizumoto R, Suzuki H. Surgical anatomy of the hepatic hilum with special reference to the caudate lobe. World
J Surg. 1988; 12(1): 2-10, doi: 10.1007/BF01658479, indexed in Pubmed: 3344582.

25. Olewnik $Ł$, Waśniewska A, Polguj $M$, et al. Rare combined variations of renal, suprarenal, phrenic and accessory hepatic arteries. Surg Radiol Anat. 2018; 40(7): 743-748, doi: 10.1007/ s00276-018-2026-0, indexed in Pubmed: 29667030.

26. Piao DX, Ohtsuka A, Murakami T. Typology of abdominal arteries, with special reference to inferior phrenic arteries and their esophageal branches. Acta Med Okayama. 1998; 52(4): 189-196, doi: 10.18926/AMO/31299, indexed in Pubmed: 9781269.

27. Polguj $M$, Podgórski $M$, Hogendorf $P$, et al. Variations of the hepatobiliary vasculature including coexistence of accessory right hepatic artery with unusually arising double cystic arteries: case report and literature review. Anat Sci Int. 2014; 89(3): 195-198, doi: 10.1007/s12565013-0219-5, indexed in Pubmed: 24310410.

28. Prasanna LC, Alva R, Sneha GK, et al. Rare variations in the origin, branching pattern and course of the celiac trunk: report of two cases. Malays J Med Sci. 2016; 23(1): 77-81, indexed in Pubmed: 27540329.

29. Schnelldorfer T, Sarr MG, Adams DB. What is the duct of Luschka? A systematic review. J Gastrointest Surg. 2012; 16(3): 656-662, doi: 10.1007/s11605-011-1802-5, indexed in Pubmed: 22215244.

30. Schofield A, Hankins J, Sutherland F. A case of cholecystohepatic duct with atrophic common hepatic duct. HPB (Oxford). 2003; 5(4): 261-263, doi: 10.1080/13651820310001388, indexed in Pubmed: 18332999.

31. Spanos CP, Syrakos T. Bile leaks from the duct of Luschka (subvesical duct): a review. Langenbecks Arch Surg. 2006; 391(5): 441-447, doi: 10.1007/s00423-006-0078-9, indexed in Pubmed: 16927110.

32. Terayama H, Yi SQ, Tanaka O, et al. Common and separate origins of the left and right inferior phrenic artery with a review of the literature. Folia Morphol. 2017; 76(3): 408-413, doi: 10.5603/FM.a2017.0025, indexed in Pubmed: 28281724.

33. Wang Yi, Cheng C, Wang Lu, et al. Anatomical variations in the origins of the celiac axis and the superior mesenteric artery: MDCT angiographic findings and their probable embryological mechanisms. Eur Radiol. 2014; 24(8): 1777-1784, doi: 10.1007/s00330-014-3215-9, indexed in Pubmed: 24859597.

34. Watson CJE, Harper SJF. Anatomical variation and its management in transplantation. Am J Transplant. 2015; 15(6): 1459-1471, doi: 10.1111/ajt.13310, indexed in Pubmed: 25981150.

35. Whitley A, Oliverius $\mathrm{M}$, Kocián $\mathrm{P}$, et al. Variations of the celiac trunk investigated by multidetector computed tomography: Systematic review and meta-analysis with clinical correlations. Clin Anat. 2020; 33(8): 1249-1262, doi: 10.1002/ca.23576, indexed in Pubmed: 32012339.

36. Yamagami T, Nakamura T, lida $S$, et al. Embolization of the right gastric artery before hepatic arterial infusion chemotherapy to prevent gastric mucosal lesions: approach through the hepatic artery versus the left gastric artery. Am J Roentgenol. 2002; 179(6): 1605-1610, doi: 10.2214/ ajr.179.6.1791605, indexed in Pubmed: 12438063.

37. Yi SQ, Li J, Terayama H, et al. A rare case of inferior mesenteric artery arising from the superior mesenteric artery, with a review of the review of the literature. Surg Radiol Anat. 2008; 30(2): 159-165, doi: 10.1007/s00276-0070298-x, indexed in Pubmed: 18189117. 